\title{
Polygyny as a Strategy for Controlling Male SEXuality To Secure ChILd SuRVIVAL
}

\author{
Farid Pazhoohi \\ School of Psychology, University of Minho, Braga, Portugal. \\ pazhoohi@gmail.com
}

\begin{abstract}
Cultural variations may have evolved as adaptations to environments. According to the parental investment theory, men tend to more actively seek short-term matings and possess a greater preference for a variety of sex partners than do women. Due to the difficulty of ensuring child survival in more demanding environments paternal care becomes vital. Here it is hypothesized that in harsh environments cultural practices have developed allowing men to have access to multiple partners while simultaneously increasing child survivorship through paternal investment. The results show that the child mortality factors are correlated with the prevalence of polygyny across African countries. It is suggested that in these regions, presumably cultural practices concerning polygyny secure paternal investment in putative children by avoiding out-of-wedlock extra-pair matings while allowing in-wedlock multiple mates. Finally, this paper refines some ambiguity regarding strategic pluralism theory described by Schmitt (2005) concerning the prevalence of polygyny in demanding environments.
\end{abstract}

Keywords: Polygyny, child survival, parental investment, demanding environments, cultural variations.

\section{INTRODUCTION}

\section{Parental Investment}

Robert Trivers defines parental investment as "any investment by the parent in an individual offspring that increases the offspring's chance of surviving at the cost of the parent's ability to invest in other offspring" (Trivers, 1972, p. 55). The sex difference in the investment of resources in fertilization and gestation affects reproductive strategies, 
so the less investing sex (usually the males) tend to increase their number of offspring by mating with several partners, which is not the same for the other sex (usually the females) (Trivers, 1972). It takes a woman's investment of internal fertilization, placentation, gestation and lactation while a man's minimum investment can be as small as a single act of sex. Biological and psychological evidence suggests men devote a larger proportion of their total mating effort to short-term mating (Bjorklund \& Shackelford, 1999; Buss \& Schmitt, 1993; Oliver \& Hyde, 1993). Regardless of the mating system, females are on average choosier than males and choosiness increases with risk of parental investment (Kenrick, Sadalla, Groth, \& Trost, 1990; Woodward \& Richards, 2005). Although other researchers suggest that there is no gender difference in seeking shortterm relationships and men and women have no distinct mating mechanism (Miller, Pedersen, \& Putcha-Bhagavatula, 2005; Pedersen, Putcha-Bhagavatula, \& Miller, 2011), cross-cultural investigations confirm sex differences in short-term mating preferences (Schmitt, 2003). Men in contrast to women tend to more actively seek short-term matings, possess a greater preference for a variety of sexual partners and require less time to elapse before consenting to sexual intercourse (Schmitt, 2003; Schmitt, Shackelford, \& Buss, 2001; Schmitt, Shackelford, Duntley, Tooke, \& Buss, 2001).

Unlike most mammals, human males often invest more than just the initial contribution of gametes and in some circumstances they would provide direct and indirect investment in their children equal to that of women (Clutton-Brock, 1989; Geary, 2000). Paternal care can contribute to the fitness of both sexes, as females of socially monogamous species with biparental care produce more litters per year than those of socially monogamous species without biparental care (Lukas \& Clutton-Brock, 2013). The degree of human male parental investment is variable. It is argued that men show paternal investment if the investment reduces child mortality or provides children with a competitive advantage over their father-absent peers (Geary, 2000). The economic and reproductive cooperation of men and women, all else equal, should increase survival and lower the mortality rate of children and young adults due to increased childcare and improved nutritional status (Kaplan, Lancaster, \& Robson, 2003; Kaplan \& Lancaster, 2003). Although the amount of parental investment provided by human males is highly variable (Heath \& Hadley, 1998) and the evidence regarding the effects of paternal investment on child survival is controversial (Sear \& Mace, 2008), there is a positive relationship between paternal investment and child physical health and a negative relationship with mortality rate (Geary, 2000). Male parental investment facilitates fertility by reducing the burden of female parental investment, thus maximizing child survivorship as well as the production of offspring (Gettler, 2010; Winking, 2006). However, higher paternal investment increases the risk that a male's parental investment will be coopted by other males employing cuckolding strategies. This risk raises the perceived value of virginity and elevates the importance of chastity within marriage. Cultural practices including bride prices, virginity tests and female genital mutilation have arisen to ensure female fidelity (Daly \& Wilson, 1978, Weisfeld, 1990). 


\section{Polygyny and Sociosexuality}

Considering the practice of polygyny, the benefits from multiple mating in terms of increased production of offspring could be profound for men. By having several consecutive spouses men increase their reproductive success; in women, serial monogamy is not associated with increased number of children (Jokela, Rotkirch, Rickard, Pettay, \& Lummaa, 2010). Gangestad and Simpson (2000) developed strategic pluralism theory which associates variability in human mating tactics with environmental factors. In ecologically adverse or highly competitive situations, male provisioning of food or other resources and high levels of parental investment are critical to rearing successful offspring (MacDonald, 1997; MacDonald, 1999). Based on strategic pluralism theory, in environments where paternal care is needed and valued, women are less likely to engage in short-term mating and extra-pair mating and men should devote greater effort to parental investment (Gangestad \& Simpson, 2000; Schmitt, 2005). On this basis, Schmitt (2005) hypothesized that in cultures with more demanding environments (e.g., higher stress, fewer resources, higher mortality), people should be more monogamous. These researchers postulated, conversely, that in cultures where biparental care is less necessary for successful child-rearing, monogamy should be less prevalent (Gangestad \& Simpson, 2000; Schmitt, 2005).

To test this hypothesis, Schmitt (2005) used the Sociosexual Orientation Inventory (SOI), which is a seven-item self-report survey designed to measure restricted versus unrestricted sociosexuality (Simpson, 1998; Simpson \& Gangestad, 1991). The SOI indicates whether individuals are engaged in extra-pair and short-term relationships, in long-term relationships, or are faithful. Those who score low on SOI (i.e. restricted sociosexual orientation) tend toward monogamy, prolonged courtship, and heavy emotional investment in long-term relationships, while those residing at the high end of sociosexuality (i.e. unrestricted in mating orientation) tend toward promiscuity, are quick to have sex, and experience lower levels of romantic relationship closeness (Simpson \& Gangestad, 1991). The questions of the SOI investigate attitudes to sociosexual variation, which is not synonymous with the actual prevalence of polygyny across nations, nor an accurate dichotomy to describe it. These authors do not distinguish between the prevalence of sexual infidelity and short-term relationship (which their study investigates) and the cross-cultural practice of polygyny, which could occur as a long-term and faithful relationship with the consent of previous wives. While the results of Schmitt (2005) show that as resources diminish and environments become deadlier, sociosexual levels become more monogamous, it should be noted that monogamy/polygyny and sociosexual orientation are not the same concepts and do not have the same implications in the real world. Polygyny is defined as marriage between one man and more than one woman concurrently while sociosexuality is defined as the individual difference in willingness to engage in sexual activity outside of a committed relationship. Therefore, the SOI is not an indicator of prevalence of polygyny across nations, and results of Schmitt (2005) study could be interpreted as the self-reported incentives for short-term versus long-term mating across nations. In contrary to Schmitt (2005) findings, it is shown that in highly demanding environments such as Africa, more polygynous sexual strategies are practiced (Tertilt, 2005). Polygyny is prevalent in subSaharan Africa and 28 countries within this region have polygyny rates of more than 10 
percent (Tertilt, 2005). Additionally, in contrast to Schmitt (2005), Thornhill and Fincher hypothesize that "high parasite stress generates high variance in genetic and phenotypic quality, and thus it can be more adaptive for a woman to pair with a man who has a wife (or wives) than to engage in a monogamous marriage" (p.172; Thornhill and Fincher, 2014). In a cooperative female choice mating system, additional co-wives can increase each other's fitness, buttressing against loss of paternal investment from disease or death as well as loss of resources diverted to short term pairings (Altmann, Wagner \& Lenington, 1977).

\section{Current Study}

The current study hypothesizes that in harsh and demanding environments where the cost of paternal investment is higher, cultural practices have emerged that require men to support their current wives and offspring while legally obtaining new wives. As argued above, due to the higher rates of child mortality in these regions, and the higher cost of paternal investment, men's preferences for multiple partners is allowed through the practice of polygyny, to support child survival and permit male preferences for multiple partners. It is known that men are able to carry out short-term tactics successfully regardless of environmental factors (Gangestad \& Simpson, 2000). Therefore, if men of harsh environments abandon their mates for pursuing new mates, according to strategic pluralism theory, the cost of child survival would be heavy (Schmitt, 2005). Therefore, cultural institutions should allow men to have multiple wives to support both child survival through their paternal investment and men's preference for the variety of sexual partners (Buss \& Schmitt, 1993). The implication would be that in these regions cultural practices should allow polygyny while enforcing strict provisions against the threats of infidelity. In this study, the link between practice of polygyny and child survival factors is investigated by looking at the relationship between the prevalence of polygyny and the national health index (including child survival factors) across 37 African countries.

There are however other proposed causes for the practice of polygyny, such as the scarcity of men due to migration (Dalton \& Leung, 2011), pathogen defense (Barber, 2008; Low, 1990), low savings rates (Tertilt, 2005) and higher fertility (Tertilt, 2003; Tertilt, 2005). In addition to the relationship of health hardship and child survival with the prevalence of polygyny, in this study, the relationship between prevalence of polygyny, Gini coefficient (an indicator of income inequality within nations), sex ratio and Gross Domestic Product (GDP) is investigated.

Another contributing factor to the prevalence of the polygyny could be male's resource holding power (Emlen \& Oring, 1977). It is argued that in environments where resources are unequally distributed, wealthy men would enjoy access to more mates than poor men (Gould, Moav \& Simhon, 2008). Accordingly, Heath and Hadley (1998) using retrospect data from United States, and Jacoby (1995) using data from Côte d'Ivoire confirmed this hypothesis. Therefore, in the current study, the relationship between men's resource holding power and the prevalence of polygyny based on gender difference in property ownership across African countries is investigated.

Although most world's major religions oppose the practice of polygyny, some religions such as Islam and traditional African religions permit this (Barber, 2008). Barber (2008) suggested that religious views could be considered as a form of cultural determination and as a null hypothesis against which adaptationist interpretations may 
be evaluated. He coded the countries as having religions favorable to polygyny and showed that affiliation to religions that allow polygyny has no influence on the practice of polygyny. Therefore, in addition to above variables, in this study the relationship between the importance of religion in daily life (which better predicts the influence of religion on one's behavior compared with religious affiliation) and the prevalence of polygyny across African countries is investigated to see to what extent polygyny is influenced by religion.

\section{MATERIALS AND METHOD}

To test this hypothesis, data on the prevalence of polygyny, the national health index (including child survival factors), sex ratio, importance of religion, Gini coefficient, Gross Domestic Product (GDP) and property ownership (house and land) for 37 African countries were used. National Health Index (NHI) data from the World Health Organization Statistical Information System (WHOSIS www.who.int/whosis) for 37 countries were used to estimate nations' general health, which consisted of eight items: neonatal mortality rate, infant mortality rate, under- 5 mortality rate, adult mortality rate, life expectancy at birth, maternal mortality rate, healthy life expectancy, and years of life lost to communicable diseases. NHI was calculated using a principal components analysis to obtain a single composite variable for each of the countries (see Marcinkowska et al., 2014; Pazhoohi, Lang, Xygalatas \& Grammer, 2017). The obtained values were multiplied by -1 , so that higher values of NHI reflect better health of a nation. Data on polygyny were used from Demographic and Health Survey Program (http://dhsprogram.com/) and data for GDP and Gini coefficient were taken from World Bank (see Table 1). Gini coefficient is an indicator of income inequality and a high coefficient means a high level of inequality. Data on sex ratio and property ownership were collected from United Nations Statistics Department (http:// unstats.un.org/). Importance of religion data were taken from a Gallup Organization survey based on telephone and face-to-face interviews conducted in 2009 with approximately 1,000 adults in each country (Gallup, 2009) asking "is religion an important part of your daily life?" The importance of religion for each country was calculated as the percentage of those who answered affirmatively.

\section{RESULTS}

A linear regression was used to examine the relationship between the practice of polygyny as a dependent variable and the NHI, GDP, Gini coefficient and sex ratio, as predictors. A multiple regression analysis revealed a significant negative correlation between NHI and the practice of polygyny $(\beta=-.386, t=-2.476, p=.018)$, suggesting that as the health condition decreases the prevalence of polygyny increases. The regression equation was significant, $\mathrm{F}(1,35)=6.131, \mathrm{p}=.018, \mathrm{R} 2=.149$. After adding the GDP, Gini coefficient and sex ratio, the relationship between NHI and the practice of polygyny remained significant $(\beta=-.389, \mathrm{t}=-2.451, \mathrm{p}=.020)$. The regression equation was significant $(\mathrm{F}(4,32)=2.975, \mathrm{p}=.034, \mathrm{R} 2=.271)$, while sex ratio $(\beta=-.231, \mathrm{t}=$ $-1.461, \mathrm{p}=.154)$, Gini coefficient $(\beta=-.234, \mathrm{t}=-1.514, \mathrm{p}=.140)$ and GDP $(\beta=-.107, \mathrm{t}$ 
$=-.664, \mathrm{p}=.511)$ were not predictors of the prevalence of polygyny. It should be cautioned that data on the importance of the religion was not available for all the countries in this study, therefore the importance of religion was not included in the regression model. Therefore, another linear regression was used to examine the relationship between the importance of religion and the prevalence of polygyny across 22 countries. There was no significant correlation between the importance of religion and the prevalence of polygyny $(\beta=-.202, t=-.924, p=.366, \mathrm{R} 2=.041)$.

Table 1: Prevalence of polygyny (percentage of currently married or in union men who have two or more wives), sex ratio, importance of religion, Gini coefficient and percentage of house and land ownership by men and women in African countries $(\mathrm{N}=37)$.

\begin{tabular}{|c|c|c|c|c|c|c|c|c|}
\hline Country & $\begin{array}{l}\text { Poly- } \\
\text { gyny }\end{array}$ & $\begin{array}{l}\text { Sex Ratio } \\
\text { (women/ } \\
100 \text { men) }\end{array}$ & $\begin{array}{l}\text { Impor- } \\
\text { tance of } \\
\text { Religion }\end{array}$ & $\begin{array}{c}\text { Gini } \\
\text { Coefficient }\end{array}$ & $\begin{array}{c}\text { Women } \\
\text { own a } \\
\text { house } \\
(\%)\end{array}$ & $\begin{array}{c}\text { Women } \\
\text { own } \\
\text { land } \\
(\%)\end{array}$ & $\begin{array}{c}\text { Men } \\
\text { own a } \\
\text { house } \\
(\%)\end{array}$ & $\begin{array}{c}\text { Men } \\
\text { own } \\
\text { land } \\
(\%)\end{array}$ \\
\hline Benin & 22.4 & 103 & - & 43.5 & 5.2 & 8.2 & 56.5 & 43.6 \\
\hline Burkina Faso & 25 & 101 & 88 & 39.8 & 5.8 & 7 & 37.2 & 35.2 \\
\hline Burundi & 2.8 & 104 & 98 & 33.4 & 8.4 & 8.1 & 53.3 & 43.3 \\
\hline $\begin{array}{l}\text { Cameroon } \\
\text { Central }\end{array}$ & 15.6 & 100 & 96 & 42.8 & 15.5 & 16.4 & - & - \\
\hline $\begin{array}{l}\text { African } \\
\text { Republic }\end{array}$ & 12 & 103 & - & 56.2 & - & - & - & - \\
\hline Chad & 28 & 101 & 95 & 43.3 & 8.2 & 13.6 & 50.3 & 13.5 \\
\hline Comoros & 11.3 & 98 & 97 & 64.3 & 42 & 32.9 & 15.5 & 13.5 \\
\hline $\begin{array}{l}\text { Congo } \\
\text { Congo, }\end{array}$ & 7.7 & 100 & - & 42.1 & 7.3 & 7.7 & - & - \\
\hline $\begin{array}{l}\text { Democratic } \\
\text { Republic }\end{array}$ & 15.4 & 101 & 94 & 40.2 & 6.4 & 7.6 & 28.5 & 21.8 \\
\hline Côte d'Ivoire & 16.5 & 97 & 88 & 43.2 & 7 & 6.5 & 29.3 & 30.9 \\
\hline Eritrea & 5.3 & 103 & 99 & 31.3 & - & - & - & - \\
\hline Ethiopia & 5.5 & 101 & 99 & 33.2 & 11.1 & 10.3 & 27.1 & 26.8 \\
\hline Gabon & 8.2 & 99 & - & 41.5 & 8.3 & 8.6 & - & - \\
\hline Gambia & 20.2 & 103 & - & 47.3 & 5.1 & 4.4 & 17.7 & 15 \\
\hline Ghana & 7.8 & 97 & 95 & 42.8 & 4.3 & 8.1 & 21 & 28.2 \\
\hline Guinea & 30.5 & 98 & - & 33.7 & 5.1 & 6.2 & 35.9 & 29.4 \\
\hline Kenya & 6 & 100 & 94 & 47.7 & 7.9 & 7.1 & 37.8 & 30.2 \\
\hline Lesotho & 2.5 & 103 & - & 54.2 & 7.6 & 6 & 10.7 & 11.4 \\
\hline Liberia & 5.7 & 99 & - & 36.5 & 8.4 & - & - & - \\
\hline Madagascar & 1.4 & 101 & - & 40.6 & - & - & - & - \\
\hline Malawi & 8 & 100 & 99 & 46.1 & - & - & - & - \\
\hline Mali & 22.1 & 100 & 95 & 33 & 9.8 & 9.3 & 39.2 & 34.3 \\
\hline Mauritania & 6.2 & 99 & 98 & 37.5 & - & - & - & - \\
\hline Mozambique & 12.5 & 105 & - & 45.6 & 13.9 & 12.6 & 30.5 & 28 \\
\hline Namibia & 2.8 & 101 & - & 61.3 & 13.5 & 8.5 & 18.7 & 13.7 \\
\hline Niger & 23.5 & 99 & 99 & 31.5 & 13.7 & 19.6 & 54.1 & 35.9 \\
\hline Nigeria & 16.8 & 97 & 96 & 43 & 3.8 & 4.7 & 25.6 & 26.5 \\
\hline Rwanda & 2.9 & 104 & 95 & 50.8 & 8 & 9.9 & 23.6 & 22.7 \\
\hline $\begin{array}{l}\text { Sao Tome and } \\
\text { Principe }\end{array}$ & 11.9 & 102 & - & 30.8 & - & - & - & - \\
\hline Senegal & 19.2 & 102 & 96 & 40.3 & 1 & 4.1 & 15.7 & 13.4 \\
\hline Sierra Leone & 22.4 & 104 & - & 34 & 4.9 & 5.1 & 20.4 & 19.7 \\
\hline Swaziland & 5.3 & 103 & - & 51.5 & - & - & - & - \\
\hline Tanzania & 9.7 & 100 & 89 & 37.8 & - & - & - & - \\
\hline Togo & 18.5 & 102 & - & 46 & 2.7 & 4.5 & 26.9 & 28.6 \\
\hline Uganda & 16.8 & 100 & 93 & 42.4 & 8.9 & 9.9 & 45.5 & 40.9 \\
\hline Zambia & 7.8 & 99 & 95 & 55.6 & 9.4 & 6.7 & 23.9 & 19.5 \\
\hline Zimbabwe & 5 & 102 & 88 & 50.1 & 9.2 & 8.9 & 15.4 & 16.7 \\
\hline
\end{tabular}


A Pearson correlation coefficient was used to examine the relationship between the prevalence of polygyny across African countries, NHI, GDP per capita, sex ratio and importance of religion in these countries. Results showed that the prevalence of polygyny across African nations is negatively correlated with national health index, suggesting that as the overall health condition increases, the practice of polygyny decreases, $r(37)=-.38, p=.018$. No significant correlation was observed between the prevalence of polygyny and GDP per capita $(\mathrm{r}(37)=-.19, \mathrm{p}=.243)$, Gini $(\mathrm{r}(37)=-.29, \mathrm{p}$ $=.073)$, sex ratio $(\mathrm{r}(37)=-.13, \mathrm{p}=.444)$, and importance of religion $(\mathrm{r}(22)=-.20, \mathrm{p}=$. 366), see Table 2.

The gender inequity in house and land ownership was obtained by calculating the difference between the percentage of the men and women owning a house or owning land. There was a positive correlation between the prevalence of polygyny and the gender inequity in house ownership $(\mathrm{r}(25)=.45, \mathrm{p}=.021)$, however no relationship was found for the land ownership $(\mathrm{r}(25)=.19, \mathrm{p}=.354)$.

Table 2: . Pearson correlation between prevalence of polygyny, GDP, NHI, Gini coefficient, sex ratio and importance of religion $(\mathrm{N}=37)$.

\begin{tabular}{|c|c|c|c|c|c|c|}
\hline Variables & 1 & 2 & 3 & 4 & 5 & 6 \\
\hline 1. Prevalence of Polygyny & - & & & & & \\
\hline 2. GNI & -.19 & - & & & & \\
\hline 3. NHI & $-.38^{*}$ & .25 & - & & & \\
\hline 4. Sex Ratio & -.13 & -.23 & -.21 & - & & \\
\hline 5. Importance of Religion & -.20 & -.01 & .13 & .10 & - & \\
\hline 6. Gini Coefficient & -.29 & .19 & -.09 & .03 & -.20 & - \\
\hline
\end{tabular}

Pearson correlation coefficients were computed to assess the relationship between the practice of polygyny and each national health components (Table 3). There were positive correlations between the prevalence of polygyny and infant mortality rate, under-5 mortality rate and neonatal mortality rate. Adult mortality rate, maternal mortality rate, healthy life expectancy, and years of life lost to communicable diseases were not correlated with the prevalence of polygyny. Life expectancy at birth was negatively correlated with the prevalence of polygyny.

Table 3: . Summary of correlation analysis for national health variables and prevalence of polygyny $(\mathrm{N}=37)$.

\begin{tabular}{lcc}
\hline \multicolumn{1}{c}{ Variables } & Pearson correlation $(\mathrm{r})$ & $p$ value \\
\hline Adult mortality rate & -.058 & .734 \\
Infant mortality rate & .562 & $.001^{* *}$ \\
Under-5 mortality rate & .659 & $.001^{* *}$ \\
Neonatal mortality rate & .474 & $.003^{* *}$ \\
Maternal mortality rate & .284 & .089 \\
Life expectancy at birth & -.378 & $.021^{*}$ \\
Healthy life expectancy & -.016 & .902 \\
Years of life lost to communicable diseases & -.021 & .902 \\
\hline${ }^{*} p<.05 ;{ }^{* *} p<.01$ & &
\end{tabular}




\section{DISCUSSION}

The results of this study showed that health hardship correlates with the prevalence of polygyny in African countries. In particular, the result of this study showed that it is child early mortality factors (i.e. infant mortality rate, under-5 mortality rate, neonatal mortality rate and life expectancy at birth) that have relationship with the practice of polygyny, not other health hardship factors. This suggests that in harsh environments, where child mortality is higher, the prevalence of polygyny practice is higher. It should be cautioned that no causal relationship could be derived from these correlations. However, as human cultural practices and animal mating systems are dependent on environmental conditions and ecological factors, not the other way around (Emlen \& Oring, 1977; Schmitt, 2005), it could be interpreted that in the demanding environments, polygyny emerged to assuage the problem of early mortality. Consistently, Fenske (2015) showed that the decline in child mortality in Africa results in decreased prevalence of polygyny. Moreover, Tertilt (2005) demonstrated that banning polygyny in African countries decreases fertility by $40 \%$. Additionally, compared to other subSaharan African countries, in highly polygynous countries total fertility rate and survival ( 1 and 5 years of age) are higher while infant mortality rate and child mortality rate are similar (Tertilt, 2005, Table 1). Consistently, Gibson and Mace (2007) showed that first wives of polygynous husbands in rural Ethiopia do better than monogamously married women in terms of child survival. Under harsh and demanding environments where the cost of paternal investment is higher, cultural and religious practices seem to reinforce fidelity and condemn promiscuity (Pazhoohi et al., 2017). Therefore, it is reasonable to argue that in these regions, cultural practices exist to dissuade men from defecting from any mating, thereby promoting paternal investment. Paternal investment is attained through the increase of confidence in paternity which would be secured through higher levels of mate guarding per se. If we consider that under harsh and demanding environments cultural practices favor fidelity due to the cost of child survival (Pazhoohi et al., 2017), then it could be argued that in these regions men's preference for having extra mates is reinforced legally through having multiple wives to secure child survival. In other words, because of the importance of paternal care in harsher environments, men should invest more in their children: if they want to have more mates, they are allowed to and should do so through legal marriage while they are obliged to support their previous children from the previous relationships/wives.

Additionally, sex ratio, GDP and Gini coefficient were not predictors of polygyny in African countries and also importance of religion did not correlate with the prevalence of polygyny. This is consistent with Barber (2008) who showed that religion, Gini coefficient, sex ratio and GDP do not correlate with the prevalence of polygyny. Although, Barber (2008) found no relationship in correlational analysis, in a regression analysis that he modeled, significant effects for Gini and sex ratio on polygyny were found. The difference in the regression results found here with those of Barber (2008) could be due to the difference in the predictors included in the regression models. Also, this difference could be due to the difference in the countries included in these two studies, as Barber excluded those countries in which the prevalence of polygyny is less than 5\%, while included non-African countries into the analysis. Overall, income inequality (Gini coefficient) and GDP were not associated with the prevalence of 
polygyny, indicating that practice of polygyny might not be related to the inequity of income and national economic performance. It should be noted that neither GDP nor Gini coefficient are accurate indicators of the distribution of wealth at household level. However, the inequity between men and women ownership of house was positively associated with the polygyny. The latter shows as the property inequity (i.e. house ownership, but not land ownership) between men and women increases (in favor of men), the prevalence of polygyny increases, confirming male's resource holding power (Emlen \& Oring, 1977; Mulder, 1990) across African countries. Finally, consistent with Tertilt (2005), the current study found no relationship between the current prevalence of polygyny and sex ratio at the national level, however ethnic groups that historically affected by the slave trades tended to have more polygynous marriages in the early twentieth century (Dalton \& Leung, 2011).

Previous studies suggested that as resources diminish and environments become deadlier, sociosexual levels lower and individuals become more monogamous or restricted (Gangestad \& Simpson, 2000; Schmitt, 2005). While under such circumstances sociosexual levels become restricted, results of the current study shows that the prevalence of polygyny increases. It should be cautioned that the Sociosexual Orientation Inventory measures the self-reported inclination towards infidelity and short-term matings and does not deal with the actual prevalence of monogamy/polygyny and fails to show people's behavior regarding the number of long-term mates.

Another explanation in addition to the role of paternal investment in interpreting the results could be that polygyny would increase child survival because more related people in close proximity (i.e. co-wives) enhance cooperative breeding. Polygyny in harsh environments might result in increased survivorship of children because of enforced paternal investment in children from multiple wives and a division and allocation of maternal investment among multiple women (Gibson \& Mace, 2007). Second and additional wives may work cooperatively together to raise children, facilitating their own reproductive success and that of the common father. The practice of polygyny could also be considered in the light of kin selection. Recently, it is shown the northern lapwing females that shared polygynous dyads were on average twice as closely related (genetically) as were random females (Grønstøl, Blomqvist, Pauliny \& Wagner, 2015). Therefore, it would be interesting to investigate human polygyny in terms of kin selection in the future.

Another interesting hypothesis for the future research to follow would be to investigate to what degree sexual infidelity is associated with the polygyny or whether there is more sexual infidelity with monogamy than polygyny. In the regions where polygynous marriages are allowed men potentially have access to multiple mates and maybe they explore these chances more than men in regions where monogamy is enforced. Therefore, less out-of-wedlock promiscuity and less infidelity is predicted for men where polygyny is allowed. In contrast, paternal investment and overall support per wife may be low in a polygynous marriage which might direct these wives to seek other men's support than their husbands, hence an increase in female infidelity.

It should be noted that the current paper does not consider the practice of polygyny to be exclusively influenced by child survival. This paper introduces the importance of paternal investment on child survival in demanding regions of the world in addition to the above mentioned causes for the practice of polygyny. Overall, the current paper adds 
the role of child survival and paternal investment to the existing literature regarding the prevalence of polygyny in African countries.

\section{ACKNOWLEDGEMENTS}

The author would like to thank James F. Doyle whose valuable comments and contribution improved the manuscript. Also the author would like to express thanks to the associate editor and two anonymous reviewers who commented on the earlier draft of this paper. FP receives funding from FCT Portugal through grant SFRH/BD/ $114366 / 2016$

\section{REFERENCES}

Altmann, S. A., Wagner, S. S., \& Lenington, S. (1977). Two models for the evolution of polygyny. Behavioral Ecology and Sociobiology, 2(4), 397-410. DOI

Barber, N. (2008). Explaining cross-national differences in polygyny intensity: Resourcedefense, sex ratio, and infectious diseases. Cross-Cultural Research, 42, 103-117. DOI

Bjorklund, D. F., \& Shackelford, T. K. (1999). Differences in parental investment contribute to important differences between women and men. Current Directions in Psychological Science, 8, 86-89. DOI

Buss, D. M., \& Schmitt, D. P. (1993). Sexual strategies theory: An evolutionary perspective on human mating. Psychological Review, 100, 204-232. DOI

Clutton-Brock, T. H. (1989). Mammalian mating systems. Proceedings of the Royal Society of London B, 236, 339-372. DOI

Dalton, J., \& Leung, T. (2011). Why is polygyny more prevalent in western africa? An African slave trade perspective. Working paper. DOI

Daly, M. \& Wilson, M. (1978) Sex, evolution and behavior. Duxbury Press.

DeBruine, L. M., Jones, B. C., Crawford, J. R., Welling, L. L. M., \& Little, A. C. (2010). The health of a nation predicts their mate preferences: cross-cultural variation in women's preferences for masculinized male faces. Proceedings of the Royal Society B: Biological Sciences, 277(1692), 2405-2410. DOI

Emlen, S. T., \& Oring, L. W. (1977). Ecology, sexual selection, and the evolution of mating systems. Science, 197(4300), 215-223. DOI

Fenske, J. (2015). African polygamy: past and present. Journal of Development Economics. 117, 58-73. DOI

Gallup. (2009). Religiosity Highest in World's Poorest Nations (Publication, from Gallup Organization: retrieved January, 2014 from http://www.gallup.com/)

Gangestad, S. W., \& Simpson, J. A. (2000). The evolution of human mating: Trade-offs and strategic pluralism. Behavioral and brain sciences, 23(04), 573-587. DOI

Geary, D. C. (2000). Evolution and proximate expression of human paternal investment. Psychological Bulletin, 126(1), 55-77. DOI

Gettler, L. T. (2010). Direct male care and hominin evolution: Why male-child interaction is more than a nice social idea. American Anthropologist, 112(1), 7-21. DOI

Gibson, M. A., \& Mace, R. (2007). Polygyny, reproductive success and child health in rural Ethiopia: why marry a married man? Journal of Biosocial Science, 39(02), 287-300. DOI

Gould, E., Moav, O., \& Simhon, A. (2008). The mystery of monogamy. The American Economic Review, 98(1), 333-357. DOI 
Grønstøl, G., Blomqvist, D., Pauliny, A., \& Wagner, R. H. (2015). Kin selection and polygyny: can relatedness lower the polygyny threshold? Royal Society open science, 2(6), 140409. $\underline{\mathrm{DOI}}$

Heath, K. M., \& Hadley, C. (1998). Dichotomous male reproductive strategies in a polygynous human society: Mating versus parental effort. Current Anthropology, 39, 369-374. DOI

Jacoby, H. (1995). The economics of polygyny in sub-saharan Africa: Female productivity and the demand for wives in Côte d'Ivoire. Journal of Political Economy. 103(5), 938-971. DOI

Jokela, M., Rotkirch, A., Rickard, I. J., Pettay, J., \& Lummaa, V. (2010). Serial monogamy increases reproductive success in men but not in women. Behavioral Ecology, 906-912. $\underline{\text { DOI }}$

Kaplan, H., Lancaster, J., \& Robson, A. (2003). Embodied capital and the evolutionary economics of the human life span. Population and Development Review, 29, 152-182.

Kaplan, H., \& Lancaster, J. B. (2003). An evolutionary and ecological analysis of human fertility, mating patterns and parental investment. In K. W. Wachter \& R. A. Bulatao (Eds.), Offspring: Fertility behavior in biodemographic perspective (pp. 170-223). Washington, D.C.: National Academies Press. DOI

Kenrick, D. T., Sadalla, E. K., Groth, G., \& Trost, M. R. (1990). Evolution, traits and the stages of human courtship: qualifying the parental investment mode. Journal of Personality, 58, 97-116. DOI

Low, B. S. (1990). Marriage systems and pathogen stress in human societies. American Zoologist, 30, 325-339. DOI

MacDonald, K. (1997). Life history theory and human reproductive behavior: Environmental/ contextual influences and heritable variation. Human Nature, 8, 327-359. DOI

MacDonald, K. (1999). An evolutionary perspective on human fertility. Population and Environment: A Journal of Interdisciplinary Studies, 21(2), 223-246. DOI

Marcinkowska, U., Kozlov, M., Cai, H., Contreras Garduño, J., Dixson, B., Gavita, O., et al. (2014). Cross cultural variation in men's preferences for sexual dimorphism in women faces. Proceedings of the Royal Society B: Biological Sciences, 10(4), 20130850. DOI

Miller, L. C., Pedersen, W. C., \& Putcha-Bhagavatula, A. (2005). Promiscuity in an evolved pairbonding system: Mating within and outside the pleistocene box. The Behavioral and Brain Sciences, 28, 290-291. DOI

Mulder, M. B. (1990). Kipsigis women's preferences for wealthy men: evidence for female choice in mammals? Behavioral ecology and sociobiology, 27(4), 255-264. DOI

Oliver, M. B., \& Hyde, J. S. (1993). Gender differences in sexuality: A meta-analysis. Psychological Bulletin, 114, 29-36. DOI

Pedersen, W. C., Putcha-Bhagavatula, A., \& Miller, L. C. (2011). Are men and women really that different? Examining some of Sexual Strategies Theory (SST)'s key assumptions about sex-distinct mating mechanisms. Sex Roles, 64, 629-643. DOI

Pazhoohi, F., Lang, M., Xygalatas, D., \& Grammer, K. (2017). Religious Veiling as a MateGuarding Strategy: Effects of Environmental Pressures on Cultural Practices. Evolutionary Psychological Science. DOI

Schmitt, D. P. (2003). Universal sex differences in the desire for sexual variety: Tests from 52 nations, 6 continents, and 13 islands. Journal of Personality and Social Psychology, 85, 85104. DOI

Schmitt, D. P. (2005). Sociosexuality from Argentina to Zimbabwe: A 48-nation study of sex, culture, and strategies of human mating. Behavioral and brain sciences, 28(2), 247-274. $\underline{\text { DOI }}$ 
Schmitt, D. P., Shackelford, T. K., \& Buss, D. M. (2001). Are men really more 'oriented' toward short-term mating than women? A critical review of theory and research. Psychology, Evolution \& Gender, 3, 211-239. DOI

Schmitt, D. P., Shackelford, T. K., Duntley, J., Tooke, W., \& Buss, D. M. (2001). The desire for sexual variety as a key to understanding basic human mating strategies. Personal Relationships, 8, 425-455. DOI

Sear, R., \& Mace, R. (2008). Who keeps children alive? A review of the effects of kin on child survival. Evolution and Human Behavior, 29(1), 1-18. DOI

Simpson, J. A. (1998). Sociosexual Orientation Inventory. In C. M. Davis, W. L. Yarber, R. Bauserman, G. Schreer \& S. L. Davis (Eds.), Handbook of sexuality-related measures (pp. 565-567): Sage.

Simpson, J. A., \& Gangestad, S. W. (1991). Individual differences in sociosexuality: Evidence for convergent and discriminant validity. Journal of Personality and Social Psychology, 60, 870-883. DOI

Tertilt, M. (2003). Polygyny and poverty. Job Market Paper. Retrieved February 2017 from http://piketty.pse.ens.fr/files/Tertilt2003.pdf

Tertilt, M. (2005). Polygyny, fertility, and savings. Journal of Political Economy, 113(6), 13411374. DOI

Thornhill, R. \& Fincher, C. L. (2014). The parasite-stress theory of values and sociality: Infectious disease, history and human values worldwide. Springer International Publishing. DOI

Trivers, R. L. (1972). Parental investment and sexual selection. In B. Campbell (Ed.), Sexual selection and the descent of man. Chicago, IL.

Wagner, N., \& Rieger, M. (2011). Polygamy and child health: Do babies get sick if daddy has many wives? Graduate Institute of International and Development Studies, Geneva. Retrived Februrary 2017 from http://www.natascha-wagner.com/uploads/ 9/0/1/5/9015445/costs_of_polygyny.pdf

Weisfeld, G. E. (1990). Sociobiological patterns of Arab culture. Ethology and Sociobiology, 11(1), 23-49. DOI

Winking, J. (2006). Are men really that bad as fathers? The role of men's investments. Biodemography and Social Biology, 53(1-2), 100-115. DOI

Woodward, K., \& Richards, M. H. (2005). The parental investment model and minimum mate choice criteria in humans. Behavioral Ecology, 16(1), 57-61. DOI 